- Supporting Information -

\title{
Surface-Enhanced Raman Spectroscopy for DNA Detection by Nanoparticle Assembly onto Smooth Metal Films
}

\author{
Gary Braun, Seung Joon Lee, Mark Dante, Thuc-Quyen Nguyen, Martin Moskovits*, \\ and Norbert Reich* \\ Department of Chemistry \& Biochemistry, University of California, Santa Barbara, California \\ 93106
}

\section{Experimentals}

Materials. Oligonucleotide (Integrated DNA Technologies) sequences are summarized in Table 1. Before modifying the Ag surfaces with probe DNAs, disulfides were deprotected by incubating with Reductacryl beads (Cleland's reagent, utilizing immobilized dithiothreitol) and diluted in $50 \mathrm{mM}$ sodium phosphate buffer at $\mathrm{pH} 7.4$ (PB) to $\sim 350 \mu \mathrm{M}$. All chemicals and solvents unless otherwise specified were reagent grade, and triply distilled water of resistivity greater than $18.0 \mathrm{M} \Omega \cdot \mathrm{cm}$ was used throughout.

\section{Table 1. Sequence of DNA oligonucleotides}

\begin{tabular}{|c|c|}
\hline $\begin{array}{l}\mathbf{a} \\
\text { b } \\
\mathbf{a}^{\prime} \mathbf{b}^{\prime} \\
\text { mismatch }\end{array}$ & $\begin{array}{l}5^{\prime}-\text { TCT CAA CTC GTA - 3' - }\left(\mathrm{CH}_{2}\right)_{6} \mathrm{~S}-\mathrm{S}\left(\mathrm{CH}_{2}\right)_{6} \mathrm{OH} \\
\mathrm{HO}\left(\mathrm{CH}_{2}\right)_{6} \mathrm{~S}-\mathrm{S}\left(\mathrm{CH}_{2}\right)_{6}-5^{\prime}-\mathrm{CGC} \text { ATT CAG GAT - 3' } \\
\text { 5' - TAC GAG TTG AGA ATC CTG AAT GCG - 3', } \\
\text { 5' - TAC GAG TGC GCA ATC CTG AAT GCG - 3' }\end{array}$ \\
\hline
\end{tabular}

SAMSA Fluorescein: 5-((2-(and-3)-S-(acetylmercapto)succinoyl)amino)fluorescein, *mixed isomers*, Invitrogen Corp., Catalog Number - A-685

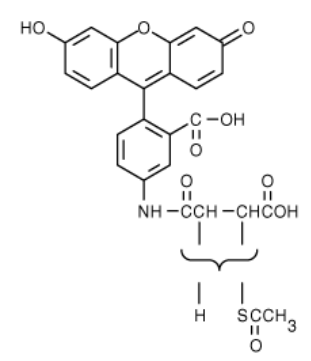

Preparation of a-modified Ag nanoparticles. Ag nanoparticles were prepared by borohydride reduction of $\mathrm{Ag}(\mathrm{I})$. Briefly, approximately $10 \mathrm{~mL}$ of $1 \times 10^{-3} \mathrm{M} \mathrm{AgNO}_{3}$ solution was added dropwise to $30 \mathrm{~mL}$ of $2 \times$ $10^{-3} \mathrm{M} \mathrm{NaBH}_{4}$ solution, which was cooled to ice temperature. The resulting yellowish-brown solution showed the characteristic surface plasmon absorption band of nano-sized Ag particles at ca. $390 \mathrm{~nm}$. The average diameter of $\mathrm{Ag}$ nanoparticles was determined to be $15 \pm 1 \mathrm{~nm}$ from transmission electron microscopy; the final concentration of the Ag colloid solution was thus estimated to be $\sim 2 \mathrm{nM}$. The colloid was stored at $4{ }^{\circ} \mathrm{C}$ until use. Thiol-DNAs were added into Ag colloid to a final concentration of $4 \mu \mathrm{M}$; two conjugates were prepared using $\mathbf{a}$ and $\mathbf{b}$ DNA. The salt aging process was performed at $4{ }^{\circ} \mathrm{C}$. After $48 \mathrm{~h}, 1$ $\mathrm{M}$ of $\mathrm{PB}$ was added into 3 additions over 3 hours to bring the solution to a concentration of $10 \mathrm{mM} \mathrm{PB} .24$ $\mathrm{h}$ later another aliquot of freshly deprotected DNA was added, increasing total DNA to $6 \mu \mathrm{M} .1 \mathrm{M} \mathrm{NaNO}_{3}$ was added to raise the salt content in $10 \mathrm{mM}$ increments not more often than every $4 \mathrm{~h}$. A color change from yellow to orange occurs if salt aging proceeds quickly. At a final salt concentration of $100 \mathrm{mM}$ 
$\mathrm{NaNO}_{3}$, the solutions were centrifuged at $14,000 \mathrm{rpm}$ at $4{ }^{\circ} \mathrm{C}$ for $\sim 30 \mathrm{~min}$ to form a soft pellet, washed with $10 \mathrm{mM}$ PB containing $100 \mathrm{mM} \mathrm{NaNO}_{3}(10 / 100$ buffer); this procedure was repeated and the final solution redispersed in this same buffer solution and stored at $4{ }^{\circ} \mathrm{C}$.

Preparation of b-modified smooth Ag film. Ag films were prepared by metal vapor deposition. A $100 \mathrm{~nm}$ Cr film was first deposited at $2 \AA / \mathrm{s}$ followed by a $100 \mathrm{~nm} \mathrm{Ag}$ (Aldrich, >99.99\%) film at $2 \AA / \mathrm{s}$ at $1 \times 10^{-6}$ Torr on a $\mathrm{Si}$ wafer. The $\mathrm{Si}$ wafer had been cleaned previously with piranha solution for 10 minutes (3:1 $\mathrm{H}_{2} \mathrm{SO}_{4}: 30 \% \mathrm{H}_{2} \mathrm{O}_{2}$ ), rinsed with deionized water, sonicated in acetone and isopropanol for $10 \mathrm{~min}$, and placed in a UV/ozone cleaner for $10 \mathrm{~min}$. WARNING: Piranha solution is very corrosive and must be handled with extreme caution; it reacts violently with organic materials and should not be stored in tightly closed vessels. The resulting $\mathrm{Ag}$ film $(1 \mathrm{~cm} \times 1 \mathrm{~cm})$ was dipped into $3.5 \mu \mathrm{M}$ of $\mathbf{b}$-DNA solution $(10 / 100$ buffer) for $24 \mathrm{~h}$. The film was then immersed in $1 \mathrm{mM}$ of aqueous 6-mercapto-1-hexanol (MCH, Fluka) solution. $\mathrm{MCH}$ was used to prevent non-specific binding of DNA on the Ag film surface, to improve hybridization efficiency to complementary strands, and to passivate the Ag surface against non-specific adsorption of NPs. The film was washed with $50 \mathrm{~mL}$ of water and dried under $\mathrm{N}_{2}$ stream. b-AgFilm was then labeled with SAMSA fluorescein (F, Molecular Probes A-685) by dipping into $10 \mu \mathrm{M}$ of $\mathbf{F}$ solution for $2 \mathrm{~h}(\mathbf{b}-\mathrm{AgFilm}-\mathbf{F}) ; 500 \mu \mathrm{M}$ of SAMSA fluorescein was prepared by removal of the acetyl protecting group with $\mathrm{NaOH}$. The solution was then neutralized with $\mathrm{HNO}_{3}$ and buffered with sodium phosphate at $\mathrm{pH} 7.4$ containing $100 \mathrm{mM} \mathrm{NaNO}_{3}$. The films were washed with $5 \mathrm{~mL}$ of $\mathrm{H}_{2} \mathrm{O}$ and dried with $\mathrm{N}_{2}$.

Hybridization. The F-labeled-b-AgFilm was dipped into a'b' (50 nM) in 10/100 buffer, and incubated at room temperature for $2 \mathrm{~h}$, then washed with 10/100 buffer leaving a moist surface. The film was immersed in $\sim 5 \mathrm{nM}$ of a-AgNPs solution (10/100 buffer) for $30 \mathrm{~min}$. After washing several times with buffer solution and briefly with $\mathrm{H}_{2} \mathrm{O}$, the hybridized surface was dried under a nitrogen stream, and then subjected to Raman measurement and AFM in the ambient conditions.
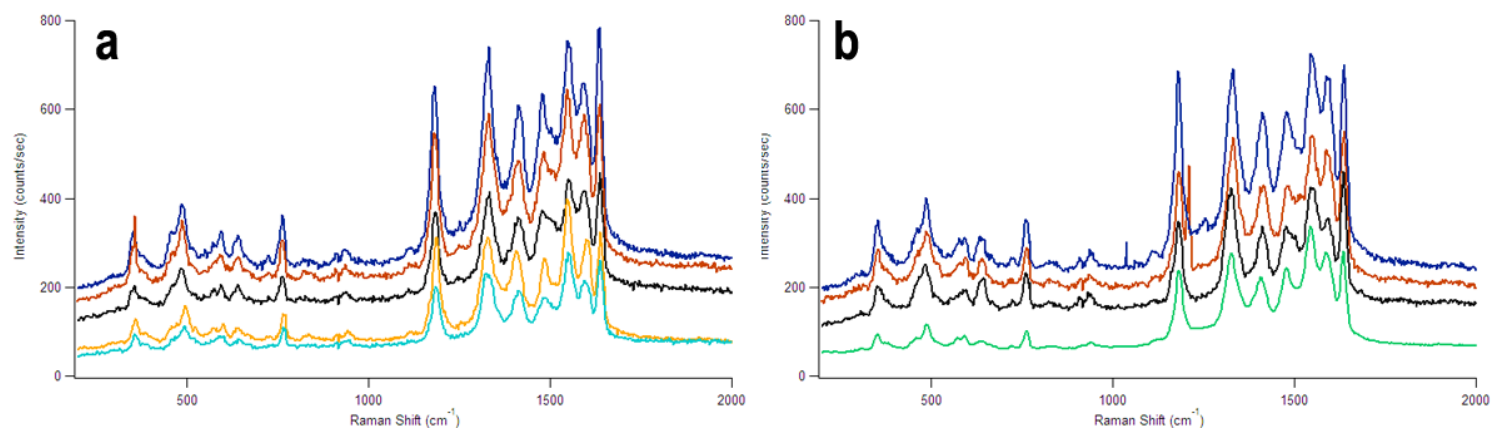

Figure 1S. (a) Spectra collected from five positions, and in (b) three positions, from two samples prepared as in Fig. 1Bb. The spectra were collected using identical instrumental conditions except for in (b), where the green curve was collected at 10 times the laser power for three times the normal duration, with the data divided by 30 to allow for comparison. The similar intensity for each spectrum indicates that the samples are fairly robust and reproducible. 


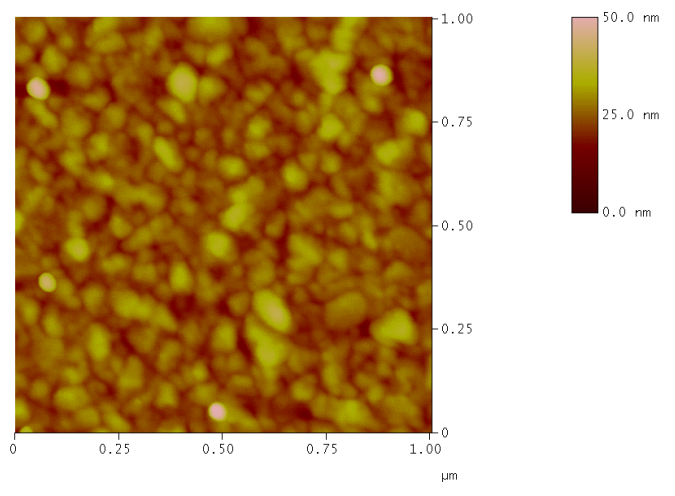

Figure 2S. AFM corresponding to a spot on Fig. 1S(a). Root mean square roughness is $\sim 3 \mathrm{~nm}$.

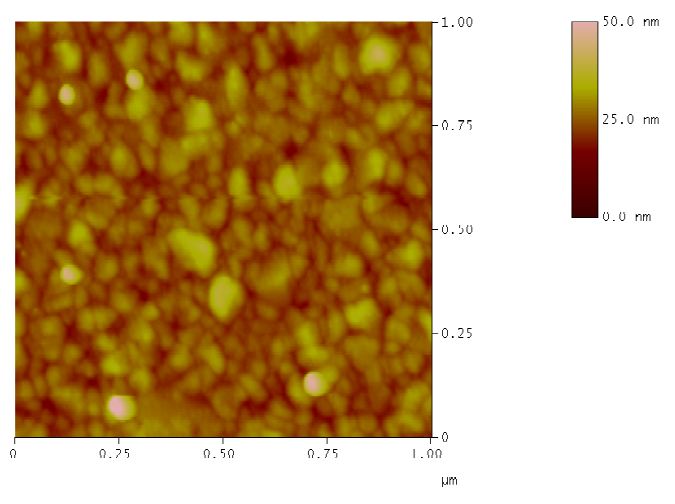

Figure 3S. AFM corresponding to a spot on Fig. $1 \mathrm{~S}(\mathrm{~b})$. Root mean square roughness is $\sim 3 \mathrm{~nm}$.

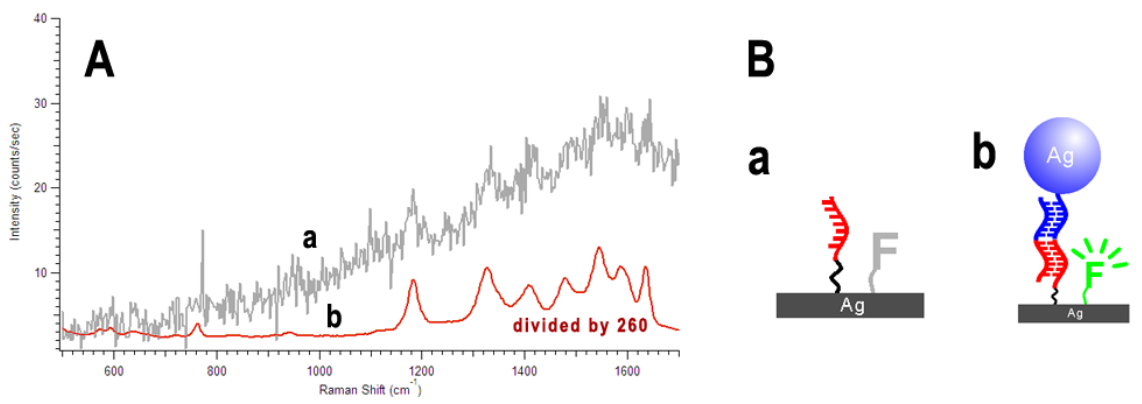

Figure 4S. (Aa) Spectrum taken before nanoparticle hybridization (sample shown in AFM image Fig. 3S). F is barely detectible on the "smooth" Ag film. (Ab) Spectrum collected after hybridization using same power and integration time, but dividing the intensity scale by a factor of 260. This factor is a measure of the signal increase due to the presence of a few NPs in the approximately one square micron laser beam. $(\mathrm{Ba}, \mathrm{Bb})$ The schema which represent the state of the system for Aa and $\mathrm{Ab}$, respectively.

Enhancement Factor. Using the information from Fig. 4SA we estimate the increase in the SERS enhancement factor (EF) for the fluorescein molecules which are located within a hot spot associated with 
the metal-film/NP sandwich. The diameter of a hot spot is estimated to be $15 \mathrm{~nm}$, which (if it is assumed to be circular) corresponds to a hot spot area of $1.8 \times 10^{-4} \mu^{2}$. Assuming the film is uniformly covered with fluorescein, the SERS signal recorded prior to the addition of the NPs, as shown in Fig. 4SAa, presumably arises from the excitation of all of the molecules in the $\sim 1 \mu \mathrm{m}^{2}$ illuminated by the laser. The signal recorded after the NPs are linked to the surface is given in Fig. 4SAb. In order to bring the Raman peak at $1185 \mathrm{~cm}^{-1}$ of this spectrum within the same order of magnitude of its counterpart in Fig. 4SAa, one had to scale it down by a factor of 260 . But spectrum 4SAa is produced by molecules covering $1 \mu \mathrm{m}^{2}$, while that shown in Fig. 4SAb originates from molecules covering the much smaller area corresponding, on average, to the area of three hot spots, i.e. $3 \times 1.8 \times 10^{-4} \mu \mathrm{m}^{2}=5.4 \times 10^{-4} \mu \mathrm{m}^{2}$. The additional enhancement factor due to the formation of the film/NP sandwich structure is, therefore, $\mathrm{EF}=260 \times 1 \mu \mathrm{m}^{2} / 5.4 \times 10^{-4} \mu \mathrm{m}^{2}=4.8$ $\mathrm{x} 10^{5}$. We stress that this is not the total SERS enhancement factor but the incremental factor due to the formation of 3 hot spots per $\mu \mathrm{m}^{2}$ each associated with the metal-film/NP sandwich.

Raman Spectroscopy. SERS measurements were performed on a LabRam microRaman system (JobinYvon/ISA) equipped with a thermoelectrically cooled CCD detector. Spectra were excited using the 514.5$\mathrm{nm}$ line of a cw Ar ion laser (SpectraPhysics 164). The incident laser beam ( $1 \mu \mathrm{m}$ of diameter) was focused, and the Raman signal was collected using a $\times 100$ objective with an NA of 0.80 . Approximately 3 $\mathrm{mW}$ of laser irradiation was used to excite the samples. The signal collection time was $10 \mathrm{sec}$.

Atomic Force Microscopy. AFM images were recorded in ambient conditions on a Digital Instruments Nanoscope IIIa scanning probe microscope. Using a V-shaped, $200 \mu \mathrm{m}$-long $\mathrm{Si}_{3} \mathrm{~N}_{4}$ cantilever with a nominal spring constant of $0.12 \mathrm{~N} / \mathrm{m}$ at a frequency of $282 \mathrm{KHz}$ (Nanoprobe, Digital Instruments), topography images were recorded in tapping mode at a scan rate of $1.2 \mathrm{~Hz}$. 